\title{
Self-regulation - the key to progress in clinical reasoning?
}

\author{
T C Postma, PhD \\ Comprehensive Patient Management, Department of Dental Management Sciences, School of Dentistry, Faculty of Health Sciences, University of Pretoria, South Africa
}

Corresponding author: T C Postma (corne.postma@up.ac.za)

Background. In 2009 a new case-based instructional design was implemented during the preclinical year of study of the undergraduate dental curriculum of the University of Pretoria, South Africa. The objective of the educational intervention was to improve the development of clinical reasoning skills. To achieve this, systematic scaffolding, relevance, integration and problem-solving were actively promoted as part of teaching and learning. A student's clinical reasoning was measured by a progress test containing 32 multiple choice questions (MCQs), formulated on a knowledgeapplication level. In 2011 it became clear that some students showed progression while others did not.

Objectives. This study was conducted to gauge the value of the case-based intervention with the aim of determining the need for further scaffolding and support, especially for non-progressing students.

Methods. The 2011 BChD IV cohort $(N=48)$ was identified for the study. Two semi-structured focus group discussions were conducted. Group 1 ( $n=8$ ) consisted of students who progressed $\geq 9 \%$, while group $2(n=8)$ comprised students who did not progress to the same extent.

Results. Both groups lauded the scaffolding that the case-based curriculum provided. Strategic thinking, goal orientation and self-regulation ability were identified in group 1. A lack of diligence, poor data-processing ability and a possible lack of interest were identified in group 2 students, who were unaware of learning opportunities.

Conclusion. There is a need for early identification of students lacking self-regulated learning and for providing timely feedback and support to progressively develop their clinical reasoning skills.

Afr J Health Professions Educ 2015;7(2):202-207. DOI:10.7196/AJHPE.411

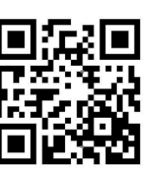

\section{Institutional context}

In 2009 the School of Dentistry, University of Pretoria, South Africa implemented a novel integrated case-based approach during the third (preclinical) year of the undergraduate dental curriculum in a subject called Comprehensive Patient Care (CPC). ${ }^{[1-4]}$ The purpose was to scaffold the transfer from the preclinical year to clinical teaching and learning. ${ }^{[5]}$ The case-based intervention was adopted in pursuit of relevance ${ }^{[5-7]}$ and integration ${ }^{[8]}$ through active learning ${ }^{[9]}$ and problem-solving approaches ${ }^{[2,10]}$ in the undergraduate dental curriculum. ${ }^{[3]}$ The novel intervention aimed to improve the assessment of clinical reasoning ${ }^{[1,12]}$ and the provision of formative feedback during the teaching, learning and assessment processes. ${ }^{[5,12]}$

Teaching and learning in the third year of study were designed to focus on tracer conditions (common oral diseases or conditions) ${ }^{[5,13,14]}$ and were generally administered through scaffolded simulation activities. ${ }^{[5]}$

The assessment plan included a test on the completion of patient administration forms used in the School. This was followed by three communication role-play exercises, simulating the communication during a clinical encounter ${ }^{[15,16]}$ based on context-rich case studies, and a comprehensive clinical examination on a peer. The formative assessment contained 5 integrated clinical reasoning portfolio case-study exercises that simulate typical clinical cases dental students would encounter in their fourth year of study. These exercises included diagnostic and treatment planning decisions and required descriptions of the student's reasoning. The final assessment comprised a progress test containing 32 multiple-choice questions (MCQs) based on a context-rich integrated case study covering the selected tracer conditions and formulated to test the ability of the students to diagnose and make decisions with regard to treatment planning. Students wrote the same test at the end of the third, fourth and fifth years of study to monitor their progress in their clinical decision-making ability. The progress test was the only standardised assessment entity that measured the outcome of clinical reasoning over time. The other assessments had a pertinent formative purpose and may have varied; they could therefore not be used to measure the development of clinical reasoning over a period of time.

All of the abovementioned activities have been integrated into clinical teaching and learning in a clinical setting during the fourth and fifth years of study.

\section{The problem}

An analysis of progress test data for 2009 - 2011 showed that some students improved their progress test scores while some did not. It should be noted that the non-progression group included students who obtained high, moderate, as well as low scores at baseline. This observation led to the investigation of possible reasons for progression and non-progression in clinical reasoning decision-making. A literature review revealed that psychological attributes such as 'self-regulated' learning and 'self-handicapping' behaviours may influence the learning of individual students.

\section{The concept of self-regulated learning}

Self-regulated learning may be defined as a proactive way of acquiring knowledge, skills and competence. ${ }^{[17]}$ Those who engage in self-regulated learning set goals for themselves, display strategic thinking, and monitor their own academic performance and effectiveness. This is in stark contrast to students who merely react to what the environment enforces on them. ${ }^{[17]}$

Zimmerman and Campillo ${ }^{[18]}$ adapted a model of self-regulated learning from a publication titled 'The nature of problem solving. There is increasing empirical evidence to support the validity of the components of the model and the interactions. Fig. 1 demonstrates the three phases of the model. The forethought phase precedes the performance phase, which is followed by a self-reflection phase. Self-reflection is often followed by a new forethought stage for further or enhanced learning. ${ }^{[17]}$ 
The forethought phase is controlled by task analysis and self-motivation beliefs. Task analysis can be described as a process of strategic planning and the setting of goals. Self-motivation beliefs include goal orientation with self-efficacy beliefs - belief in your own abilities - and an interest in the task at hand, with distinct outcome expectations. For example, expectations of the achievement of 'excellent' assessment results could be seen as an indicator of being goal orientated. ${ }^{[17]}$

The second phase is the performance, where self-control and self-observation are the key processes. Self-control is a process of selfinstruction, displaying attention and focus. The adoption of task strategies and imagery are typical processes employed by self-regulated learners during this phase. Self-monitoring is related to self-control and entails metacognitive monitoring and self-recording practices. ${ }^{[17]}$

The third phase is self-reflection, which consists of self-judgement and self-reaction. Self-judgement includes processes of self-evaluation and causal attribution. ${ }^{[17]}$ The latter may be defined as the reasons (provided by the learner) for the cause of a specific event. ${ }^{[17]}$ The learner might perceive the cause to be from an internal origin (a result of his or her personal behaviour) or an external source. Self-judgement is followed by self-reaction, based on the individual's perception of self-satisfaction. A lack of self-satisfaction might, for example, affectively stimulate a renewed forethought phase to continue the learning. Adaptations to behaviour might also be made as a result of self-evaluation. ${ }^{[17]}$

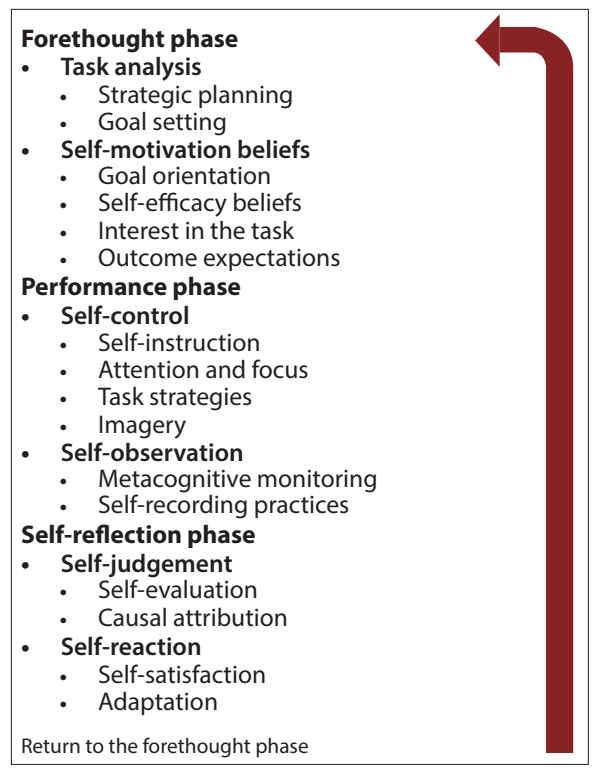

Fig. 1. The phases of self-regulated learning. ${ }^{[17]}$

\section{The concept of self- handicapping behaviour}

In contrast to self-regulated learning, there is learning that might be impeded by a student's personal behaviour. ${ }^{[19]}$ Self-handicapping may be viewed as being in direct contrast to self-regulation. Some students employ self-handicapping strategies to protect and enhance their self-esteem. ${ }^{[19]}$

Those who employ self-handicapping strategies typically postpone their learning to the last minute and might subsequently blame the circumstances and the external environment rather than their lack of ability, motivation, and diligence. ${ }^{[19]}$ Those who are guilty of self-handicapping behaviour tend to project their lack of performance or failures away from themselves in an attempt to protect their own ability and self-worth. ${ }^{[20,21]}$

Self-handicapping has a negative correlation with a goal-setting approach in the academic environment. ${ }^{[22]}$

\section{Objectives}

The first objective of this study was to compare qualitative feedback from progressing and nonprogressing fourth-year dental students with regard to the value of the case-based intervention they were exposed to in the preclinical year of study.

The second objective was to identify selfregulating and self-handicapping behaviours ${ }^{[17,18]}$ among the students, based on the differences in feedback.

The third objective was to determine the need for additional student support to improve the educational intervention further.

\section{Methods}

As the current study was part of a larger action research project that originated before 2009, the original protocol (153/2009) was amended in 2011 to include the following qualitative analysis

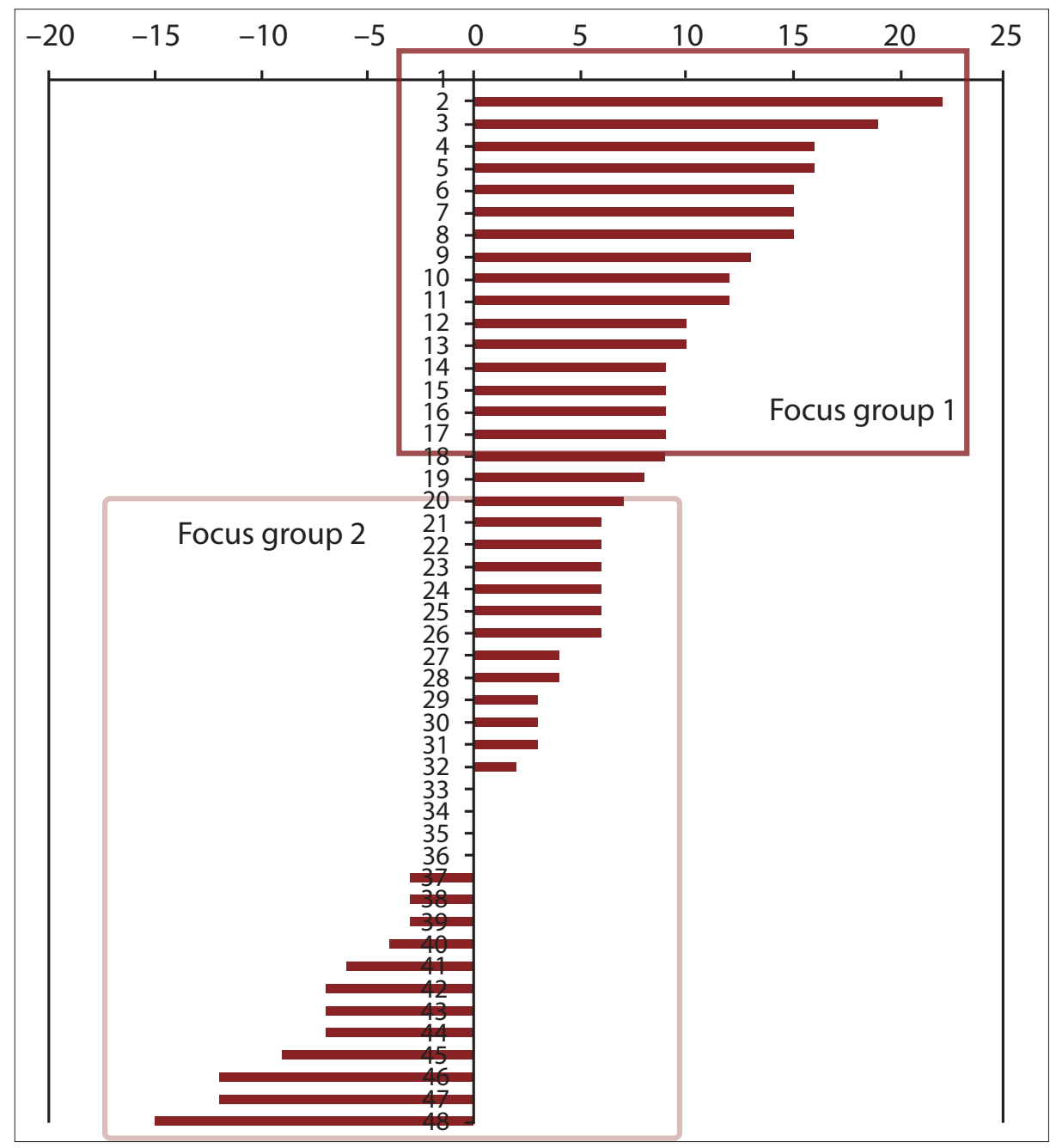

Fig. 2. Distribution of the individual progress test score (\%) differences between 2011 and 2010 for the 2011 $B C h D$ IV cohort $(\mathrm{N}=48)$. 
as part of the evaluation of the newly implemented integrated case-based approach.

\section{Sample selection}

The 2011 fourth-year BChD cohort was identified because they had the opportunity to clinically apply the knowledge they had gained in the preclinical (third) year of study. These students had completed the progress test more than once; therefore, their progress could be tracked. The fifth-year group, who were in the final phase of their undergraduate course at that stage, were not interviewed because of time constraints.

\section{Study design}

The researcher identified semi-structured focus group discussions as the method of choice for data collection. Such groups maintain a broad structure but allow for flexibility during the interview so that students may elaborate on their experiences. This may lead to the discovery of information that might have been restricted by an overly structured approach. ${ }^{[23]}$

Two groups of 8 students each from the 2011 fourth-year cohort were purposively selected by the researcher for focus group discussions. ${ }^{[23}$ These groups were arbitrarily differentiated according to their progression in terms of clinical reasoning (Fig. 2) (measured by means of the progress test), which has been described in the introduction. Focus group 1 consisted of students who appeared to have improved their progress test scores by $\geq 9 \%$. Focus group 2 comprised students who had either achieved lower progress test scores or had improved their progress test scores by $\leq 6 \%$.

\section{Informed consent}

The students gave written informed consent for their feedback to be included as part of the research project.

Table 1. Positive student feedback about the value of the third-year case-based intervention in preparation for clinical teaching and learning

Focus group 1
Relevance
- 'I also feel it was very, very relevant and the fact that it is such a practical
subject. You go out, you do the sessions, you take the patient as a case and you
do it. It is not just theory that you have to go and study. ... So, it is practical and
it is hands-on and also the type of information that is really useful. It is things
that you use every single day. It is the reason behind the theory.'

Integration

- 'So, in this subject you learn a little bit of this, and a little bit of that, and then when we got to do the treatment plan. Everything comes together; you know where everything fits in, and how this affects that, and that affects that.'

- '... OPB is, like, the whole holistic thing ....

Scaffolding

- ' $\ldots$ at the end when you knew what to do, it helped a lot to get your thinking right because you knew, okay, this is the way I have to ... ?

- ' ... and you also learn a lot of, like, diseases and names of things, and how to diagnose it ... and do the treatment for it. So it helped a lot for me.'

- 'I mean we've started the year on the 4 th floor ... and we've started looking in the mouth and we knew exactly what to do.'

- 'Okay, it did help a lot and I think it is a good thing that we have that. If we didn't have that we would have been totally lost with your first patient. I would have freaked out; I can't handle that.'

- 'We are going to use treatment planning for the rest of our lives with all our patients, and if we didn't learn it step by step with a good foundation then we never would have known how to do it. Yes, it really helped a lot. I think it gave us a good foundation.'

- 'It helps you, like, thinking on how to treat the patient, and you will actually have that much more confidence. The patient will also see that this person exactly knows what to do... ?

- '.. and then [it] also teaches you a lot about treating complex cases.'

Feedback

- 'We did the first one and then doctor ... gave us corrections with the formats. ... Yes, the first one, I did nothing right.'

\section{Focus group 2}

Relevance

- 'I think it is very relevant and I learned a lot from it.' (Translated from Afrikaans into English)

\section{Integration}

- ' ... and your perio, caries and endo and all those stuff ... everything is in there. So if you go through it you won't be surprised in the following year like [in] the fourth year. So, once you get that a patient ... is full [of] pain ... high blood pressure ... everything together'

- '.. because this is a subject that basically puts everything together, yes, that is cool.'

Scaffolding

- 'I was pretty, pretty nervous when I saw my first patient, only to find out that, luckily, I knew something.'

- 'I think it sets the basis from where you can work. It's a lot different when you get a new patient rather than a friend ... but it gives you a guideline from where you can work to, or what you can work from, or how to diagnose different caries and erosion and attrition ... So it was a good baseline for us to work from.

- 'I also think the third-year cases really helped in putting a base on how to handle a patient, and all that, so it does help. So it must continue.'

- ' ... for me, I feel it did really help a lot, like I don't think it should be changed on my side because I feel, like, okay, on some patients you won't be able to encounter everything, not all patients have the same problems ..., so I feel the cases did add something that you didn't, maybe, know, or see firsthand. So, for me it really did help'.

- 'And, also, I feel that the case studies actually did help me, like, to prioritise my treatment ... So, yes, for me it did play a role ... .'

- 'I feel the same; that it sets a baseline for you where you work from.'

Feedback

- 'I think the critique and the way they worked with us, it really helped us. I remember there was a case I had to do on Endo. I didn't know anything about Endo ... and the process sticks in my mind because of the critique. If they were lenient I would probably go with my own way of thinking ... the way they criticise, it is very beneficial for us ... . 


\section{Research}

\section{Table 2. Strategic recommendations made during focus group 1}

- '... the very first patient that a fourth-year gets handed shouldn't be a complex, complex case so that you feel lost ... So, maybe if there can be some decent screening, seeing that this is a patient ... not like a patient that needs a partial denture, an endo, four extractions ... has, like, perio on six of the teeth ... If it is just a bit of an easier case, the first one, and then they can throw you into the deep end.'

- 'But I think if they included pictures like in the beginning ... it is nice to see stuff that you've seen before especially if you have to set up a treatment plan. So I think if they can include pictures in the third-year stuff, it will make stuff so much easier.'

- 'So, if they give you, say, an example of what to do, say, on tooth 11 diagnosis, prognosis, those things, those things, next line ... I mean, it will make stuff so much easier, it will make the marking for them easier and the students will be better off.'

- 'Obviously, CPM includes Prosthetics with the treatment plan as you still have to, like at the end, maybe the patient will have to get partial dentures but he doesn't get into details ..., if they can include ... and a detailed part of Prosthetics, then it will help a lot.'

- 'I mean if we can actually get a subject like CPM for Ortho and for Prosthetics the performance will be so much better.'

- ' ... they must try to maybe broaden everything.'

- 'Yes, everything that we do in our fourth year we have to practise in our third year.'

- 'I know that some of the students, when they did partial dentures, then they said you can still save the teeth and when they got to Prosthetics they told the patient, no, all the teeth have to be extracted, and then the patient has already been to five, six, seven, eight restorative sessions and then Prosthetics tells them, no, sorry, extract the teeth. So it is not really very nice for the patient, or for the students ... so, if they can just have some correlation between them ... because otherwise you get so confused .... '

- 'You came into fourth year and you don't have a clue of how the files work, where did the patient actually get the files and the payments. The patient asks me that all the time and I don't have an idea.'

Table 3. Negative student feedback from focus group 2 about the value of the third-year case-based intervention in preparation for clinical teaching and learning

Scaffolding

- Comment 1: 'For me, the assignments or the case studies did nothing really help ... .'

- Comment 2: 'The practical work that we've done on the buddies ... did a good job for me, but the assignments ... ?'

- Comment 3: 'I think I'm hard-headed when it came to the case studies. I think they are great for other people ... but for me? I had issues with the case studies and assignments. I prefer practical and theory'.

- Comment 4: 'I prefer modelling - it stays in my head - and a little bit of theory [rather] than case studies. I know case studies is the incorporation of it, but if I will rather act in it, than trying to figure out what somebody else is thinking ... but when we come to practical and doing everything, it is good for me.'

- Comment 5: ' ... when you get into fourth year and you see your first patient and you don't know where you have to be, you don't know what to do ... and you are asking everybody and it [is] wasting a lot of time.'

- Comment 6: 'But I feel it doesn't actually teach us how to deal with difficult patients; like, I have the worst patient, like, I don't know what to do because the patient was very angry because of the way he was treated and everything ... so everything else was taken out on me ..., now, and I don't know how to control the situation and then Dr Y had to step in.'

- Comment 7: 'It is only with the third, fourth case studies it starts getting better, but the first one definitely not. If you go and look at your answers and look at someone else's answers they were totally different. There wasn't really a set way to answer anything. Yes, we were all confused about how to actually do the questions. So if there is a lecture before ... we want this and this and this - whatever - then you will know better. Because everyone's case studies look different and I was always confused about how to answer them.'

Data-processing ability

- Comment 8: 'So, for me, case studies, I don't want to lie, even my maths are like, oh yeah, very low ... .

Diligence

- Comment 9: ' ... the case studies we did, did not really prepare us for that test we wrote at the end. There were questions that I had never thought about in my life before. Unless I did not complete the case studies properly? Or did not understand them well enough?' (Translated from Afrikaans into English)

Goal orientation

- Comment 10: 'Sometimes you don't know how to prepare for it, like they say you have to go home and get this ready and do a slide show for this ... Sometimes it is a bit difficult to know what is expected of you to do ... but otherwise it is okay'.

Unaware of learning opportunities

- Comment 11: 'So, we didn't get feedback on any of the cases.'

- Comment 12: 'Feedback. Yes, because we never got feedback on the case studies, and what was expected and what the students never saw. Because everything in a case study is said for a reason, and then just to know all the reasons, then you will know what to look for in that final test.'

- Comment 13: 'Okay, I just remember we always got these pathology questions in the case studies that we were not always prepared for. They would say there is a white lesion in the back of your gums. How would you diagnose it, how would you treat it? We had no idea about pathology when we were in our third year ... I always found those questions very difficult. I understand that we also should go and study or look up things but if we just had a bit of information ... yes, if we were just a bit more prepared for it.' 


\section{Focus group procedures}

A dentist who was not directly involved with the intervention or with CPC, facilitated and voice recorded the focus groups discussion. To start the discussion, the facilitating dentist posed the following open-ended question to the students: 'In terms of your own learning, how did you experience the case studies that were used in the third year of study to train your diagnostic- and treatment-planning skills?'

The facilitator allowed the students to respond randomly in a paticipative manner. Efforts were made not to lead the students in any way during the focus group session. However, the facilitator used probes for enquiring about how the students 'experienced' and 'approached' the case-based teaching and learning. When the session stagnated the students were questioned in a sequential order - as they were seated around the table - to respond to the facilitator's questions. Eventually all students were afforded an opportunity to speak.

\section{Transcription and analysis}

An administrative member of staff of the School of Dentistry transcribed the voice data ${ }^{[23]}$ into text format. The dentist who facilitated the focus groups controlled the transcription, made corrections, and also performed thematic analysis ${ }^{[2]}$ of the data. The protocol allowed for themes to be gradually identified and added in an open-ended fashion. ${ }^{[22]}$

The researcher controlled the thematic analysis after the initial identification of themes by the facilitator of the focus groups. During this process, quotes from the discussion groups were reorganised by the researcher by merging themes with similar focus together into a single theme. ${ }^{[22]}$

The quotes identified were tabulated per theme for both the sample groups.

\section{Results}

Only the focus group 1 discussion took place as originally scheduled. Focus group 2 had to be rescheduled.

Positive feedback regarding acquisition of prior knowledge in preparation for clinical teaching and learning through the preclinical case-based approach is reported in Table 1 for both focus groups. This feedback was thematically coded as follows: relevance; integration; scaffolding; and feedback.

Constructive feedback from focus group 1 to improve the teaching and learning in CPC is given in Table 2. These comments contain a variety of suggestions to improve the existing scaffolding strategies further. Similar suggestions were not obtained from focus group 2.

Comments generally relating to deficiencies in standardisation and calibration between faculty dominated the constructive feedback in focus group 2. One of these comments was: 'So, yes, I think, just let the doctors be more on the same page.'

Negative perceptions, predominantly originating from focus group 2 about the case-based approach, are listed in Table 3. These results were thematically coded as follows: scaffolding; data-processing ability; diligence; goal orientation; unaware of learning opportunities; and attribution. In contrast to focus group 1, there were comments (Table 3) that suggest that the scaffolding (comments 1 - 7) was not adequate for all the students of the second focus group. The results from focus group 2 also suggest that some of the individual students may have had data-processing problems related to the complex case studies (comment 8) and 1 student admitted a lack of diligence (comment 9), while another indicated a lack of awareness of what was expected (comment 10). None of these themes was similarly evoked in focus group 1. Unlike the students from the first focus group, some students in group 2 did not know about the feedback given for each case study assignment (comments 11 and 12). Some of them were not aware of the introductory lecture that was given on pathological lesions in the third year of study (comments 13).

\section{Discussion}

This study sought feedback from fourth-year dental students regarding the value of the case-based interventions they were exposed to in the preclinical year of study. During the feedback process it was attempted to identify selfregulating behaviours ${ }^{[15,16]}$ in those who progressed in clinical reasoning and self-handicapping behaviours, ${ }^{[17-20]}$ in those who did not display progress. The discovery of differences in self-regulation in clinical reasoning between progressing and non-progressing students may warrant the introduction of additional scaffolding and support for students lacking self-regulation in the educational intervention.

\section{Focus group 1 (progression group) - interpretation of the feedback}

Students who improved their progress test scores over time thought that the third-year case-based intervention provided them with knowledge and skills that prepared them reasonbly well for the fourth year of study (Table 1). Positive remarks were made about the relevance of the teaching and learning, integration and the scaffolding of the transfer from the third to the fourth year of study.

The feedback provided in focus group 1 (Tables 1 and 2) can be interpreted as a positive appraisal of the preclinical case-based approach. Constructive suggestions were made to improve the educational processes - not only at CPC but also in the broader undergraduate curriculum. The students suggested the need for improved integration with disciplines such as prosthetics and orthodontics, standardisation, a need for clinical images in the supportive information and more knowledge about the administration of the hospital. These suggestions indicate the interest in the educational process and strategic thinking. The responses can also be interpreted as the students having a goal-orientated approach to providing improved care to their patients. ${ }^{[17]}$ These observations are related to the forethought phase of the self-regulation cycle (Fig. 1). ${ }^{[17]}$ The results suggest that the students may have reflected on aspects of the teaching and learning environment that could be improved so that they may improve their own clinical practice.

\section{Focus group 2 (non-progression group) - interpretation of the feedback}

This group also made a substantial number of positive comments about the educational processes, which indicates some congruence with the attitudes and behaviours of the students in focus group 1. Issues raised about relevance, integration, scaffolding and feedback were similar to those raised by focus group 1 .

Compared with the results of focus group 1, focus group 2 highlighted several observations that could be related to self-handicapping behaviours. ${ }^{[19-22]}$ The focus groups were advertised simultaneously to all parties concerned - verbally and in writing. Students from focus group 2 arrived late for the feedback session, while others did not arrive at all. Their excuse was that they could not find the unusual venue. The reasons for this behaviour remain speculative, but there appeared to be a lack of interest in the activity and a lack of proactive planning to ensure that they arrive on time. 
Comments 5 and 10 (Table 3 ) hint towards a lack of strategic planning and suboptimal goal orientation (Fig. 1). ${ }^{[17,18]}$ Comments 3, 4 and 7 suggest that some of the students may have lacked self-efficacy beliefs to meaningfully participate in the case study exercises. The students from this group (comments 11 - 13) were unaware of learning opportunities, which may also indicate absence or lack of interest during learning opportunities at the CPC unit. These observations relate to behaviours in the forethought phase of self-regulated learning and suggest that some students may have been lacking in task analysis and self-motivation beliefs (Fig. 1). ${ }^{[17,18]}$

Comments 7 and 10 (Table 3) might, however, also indicate a lack inability of self-instruction, while comment 10 is an admission of one of the students of a lack of diligence, which may be compared with a lack of focus and attention. ${ }^{[17,18]} \mathrm{A}$ lack of diligence is defined as a form of selfhandicapping behaviour. ${ }^{[19-22]}$ These observations relate to behaviours in the performance phase of self-regulated learning and suggest that some students may have been lacking self-control behaviours (Fig. 1). ${ }^{[1718]}$

Some of the negative comments may be interpreted as the students attributing their inability to perform to the inadequacies of the case-based approach. For example, they tended to blame their own inefficiencies on the instructional design (comments 6 and 9, Table 3) and a lack of feedback (comment 12). These observations imply inefficiencies in the self-reflection phase of self-regulated learning (Fig. 1) in this group. ${ }^{[17,18]}$

The negative findings of this qualitative study show that the case-based intervention may still need refinement in terms of scaffolding, feedback and student support, and suggest that scaffolding and support should not only focus on the subject matter itself, but actively provide support aimed at developing the students' self-regulating ability. Such an approach requires the early identification of students who display self-handicapping behaviours combined with appropriately designed feedback and tutor systems that could assist in the development of the students' task analyses, motivational beliefs, performance and self-reflection abilities. This may also be applicable to other modules in the curriculum, but it might also be context specific. ${ }^{[25]}$ The context of the current study is the development of clinical reasoning skills. It is pertinent to note that in terms of this study non-progressing students are not necessarily the ones who struggle to pass the course, but may be students with moderate or high marks.

\section{Conclusion}

The results of this study provide some evidence of qualitative differences in the feedback of students in terms of 'self-regulated learning' between those who showed progression in clinical reasoning and those who did not progress.
This study also suggests that the case-based intervention could further be improved by providing an additional scaffold to students who are at risk of not progressing in terms of their clinical reasoning ability. Faculty should therefore focus on the early identification of students who are unable to regulate their own learning, and the provision of timely feedback aimed at devloping self-regulation abilities.

Although the extent of the current study is small and limited to the performance of a single cohort of students, the findings may be valuable in paving the way for future similar research projects by linking actual performance to self-regulatory behaviour in an authentic teaching and learning environment.

Acknowledgement. Ms Barbara English of the Faculty of Health Sciences Research Office at the University of Pretoria is thanked for the language editing.

\section{References}

1. Postma TC. Evaluating the Impact of Adjunctive Integrated Case-based Dental Teaching and Learning on Clinical Reasoning in a Discipline-based Teaching and Learning Environment. PhD thesis. Pretoria: University of Pretoria, 2013:1-221

2. Snyman WD, Ligthelm AJ. The new Pretoria curriculum. S Afr Dent J 2000;55(11):642-648.

3. University of Pretoria, School of Dentistry. The Pretoria BChD Qualification Competencies. Pretoria: University of Pretoria, 2008.

4. Seeliger JE, Snyman WD. A new approach to undergraduate dental education. S Afr Dent J 1996;51(12):746-749. 5. Postma TC, White JG. Developing clinical reasoning in the classroom - analysis of the 4C/ID-model. Eur J Den Educ 2015;19(2):74-80. [http://dx.doi.org/10.1111/eje.12105]

6. Ashton S. Authenticity in adult learning. Int J Lifelong Educ 2010;29(1):3-19.

7. Biggs J. Enhancing teaching through constructive alignment. Higher Educ 1996;32:347-364.

8. Snyman WD, Kroon J. Vertical and horizontal integration of knowledge and skills - a working model. Eur J Dent Educ 2005;9(1):26-31.

9. Steinert Y, Snell LS. Interactive lecturing: Strategies for increasing participation in large group presentation. Med Teach 1999;21(1):37-42.

10. Harden RM, Davis MH. The continuum of problem-based learning. Med Teach 1998;20(4):317-322

11. Wass V, van der Vleuten C, Shatzer J, Jones R. Assessment of clinical competence. Lancet 2001;357(9260):945949 .

12. Norcini J, Anderson B, Bollela V, et al. Criteria for good assessment: Consensus statement and recommendations from the Ottawa 2010 Conference. Med Teach 2011;33(3):206-214. [http://dx.doi.org/10.3109/0142159X.2011.551559]

13. Kessner DM, Kalk CE, Singer J. Assessing health quality - the case for tracers. N Engl J Med 1973;288:189-194.

14. Darling MR, Daley TD. Oral pathology in the dental curriculum: A guide on what to teach. J Dent Edu 2006;70:355-360.

15. White JG, Kruger C, Snyman WD. Development and implementation of communication skills in dentistry: An example from South Africa. Eur J Dent Educ 2008;12(1):29-34. [http://dx.doi.org/10.1111/j.16000579.2007.00488.x]

16. White JG. Strategy for teaching communication skills in dentistry. S Afr Dent J 2010;65(6):260-265

17. Zimmerman BJ. Investigating self-regulation and motivation: Historical background, methodological developments,

and future prospects. Am Educ Res J 2008;45(1):166-183.
18. Zimmerman BJ, Campillo M. Motivating self-regulated problem solvers. In: Davidson JE, Sternberg RJ, eds. The 8. Zimmerman B], Campillo M. Motivating self-regulated problem solvers. In: D
nature of problem solving. New York: Cambridge University Press, 2003:239.

19. Ommundsen Y, Haugen R, Lund T. Academic self-concept, implicit theories of ability, and self-regulation
nature of problem solving. New York: Cambridge University Press, 2003:239. Ommundsen Y, Haugen R, Lund T. Academic sel
strategies. Scand J Educ Res 2005;49(5):461-474

20. Covington MV. Making the Grade: A Self-worth Perspective on Motivation and School Reform. New York Cambridge University Press, 1992.

21. Urdan T, Midgley C. Academic self-handicapping: What we know, what more is there to learn? Educ Psycho Rev 2001;13:115-138.

22. Midgley C, Urdan T. Academic self-handicapping and achievement goals: A further examination. Contemp Educ Psychol 2001;26(1):61-75.

3. Gill P, Stewart K, Treasure E, Chadwick B. Methods of data collection in qualitative research: Interviews and focus groups. Br Dent J 2008;204(6):291-295. [http://dx.doi.org/10.1038/bdj.2008.192]

24. Braun V, Clarke V. Using thematic analysis in psychology. Qual Res Psychol 2006;3(2):77-101.

25. Cleary TJ, Sandars J. Assessing self-regulatory processes during clinical skill performance: A pilot study. Med Teach 2011;33(7):e368-e374. [http://dx.doi.org/10.3109/0142159X.2011.577464] 